Psychother Psychosom 2020;89:48

DOI: $10.1159 / 000504100$

\section{Response to "International Society for Nutritional Psychiatry Research Practice Guidelines for Omega-3 Fatty Acids in the Treatment of Major Depressive Disorder" by Guu et al. (2019)}

\section{CarishaS. Thesing Femke Lamers Mariska Bot Brenda W.J.H. Penninx Yuri Milaneschi}

Amsterdam UMC, Vrije Universiteit Amsterdam, Department of Psychiatry, Amsterdam Public Health Research Institute, Amsterdam, The Netherlands

The International Society for Nutritional Psychiatry Research (ISNPR) recently published clinical guidelines for the use of omega-3 fatty acids (n-3 PUFAs) in the treatment of major depressive disorder (MDD) in this journal [1]. We praise the authors for their effort to distill clear clinical indications from complex and heterogeneous research findings. Overall, these guidelines help bringing clarity on a highly debated field - the use of nutritional supplementation in psychiatry - in which patients and clinicians were until now left without any evidence-based guidance. Nevertheless, we would like to ask for caution on a specific recommendation. The expert panel states that " $n-3$ PUFAs could be recommended as a potential prophylactic treatment for high-risk populations (alongside standard medical care)." We believe that the limited evidence currently available does not support such recommendation.

Few longitudinal studies in initially non-depressed subjects provide conflicting findings: while n-3 PUFA dietary intake estimated from food-frequency questionnaires was associated with lower risk of subsequent development of MDD or clinically relevant symptoms [2], no association was found for measured n-3 PUFA blood concentrations [3]. Nevertheless, risk estimates form observational studies in nutritional epidemiology are biased by residual confounding and reverse causation [4]. Methodologically robust studies allowing to properly estimate causal effects also do not support a role of n-3 PUFAs on the risk or depression onset. The EU-funded MooDFOOD trial [5] examined the effectiveness of multi-nutrient supplementation (including n-3 PUFAs) to prevent depression over 1 year in 1,025 overweight individuals with elevated depressive symptoms. Supplementation (vs. placebo) did not prevent the 1-year onset of MDD nor had it a beneficial impact on the 1-year course of symptoms. More recently, a study [6] applied Mendelian randomization analyses - inferring causal rela- tionship between modifiable risk factors and disease using genetic variants as natural experiment - on data from $\sim 500,000$ subjects. Findings provided no evidence of a causal role of n-3 PUFA on the risk of MDD onset. In their review of the literature, the authors of the guidelines mentioned only one prevention trial [7] on a highly specific sample of 152 subjects with chronic hepatitis C, showing an effect of n-3 PUFAs versus placebo in the prevention of major depressive episodes induced by interferon-alpha treatment.

All in all, we feel the clinical significance of preventive n-3 PUFA supplementation for MDD is not supported by adequate empirical evidence. In prevention efforts, premature translation of inadequate evidence may result in waste of resources and time, at the cost of research on more strongly grounded interventions; this risk is certainly present in this case. We agree with the ISNPR panel's suggestion on the need of "well-designed randomized controlled trials with larger sample sizes and longer duration to confirm the (preventive) efficacy of n-3 PUFAs." Until these studies become available, the recommendation on the use of n-3 PUFAs as prophylactic treatment should be reconsidered.

\section{References}

1 Guu TW, Mischoulon D, Sarris J, Hibbeln J, McNamara RK, Hamazaki $\mathrm{K}$, et al. International Society for Nutritional Psychiatry Research Practice Guidelines for Omega-3 Fatty Acids in the Treatment of Major Depressive Disorder. Psychother Psychosom. 2019;88(5):263-73.

2 Grosso G, Micek A, Marventano S, Castellano S, Mistretta A, Pajak A, et al. Dietary n-3 PUFA, fish consumption and depression: A systematic review and meta-analysis of observational studies. J Affect Disord. 2016 Nov;205:269-81.

3 Persons JE, Robinson JG, Ammann EM, Coryell WH, Espeland MA, Harris WS, et al. Omega-3 fatty acid biomarkers and subsequent depressive symptoms. Int J Geriatr Psychiatry. 2014 Jul;29(7):747-57.

4 Ioannidis JP. The Challenge of Reforming Nutritional Epidemiologic Research. JAMA. 2018 Sep;320(10):969-70.

5 Bot M, Brouwer IA, Roca M, Kohls E, Penninx BW, Watkins E, et al.; MooDFOOD Prevention Trial Investigators. Effect of Multinutrient Supplementation and Food-Related Behavioral Activation Therapy on Prevention of Major Depressive Disorder Among Overweight or Obese Adults With Subsyndromal Depressive Symptoms: The MooDFOOD Randomized Clinical Trial. JAMA. 2019 Mar;321(9):858-68.

6 Milaneschi Y, Peyrot WJ, Nivard MG, Mbarek H, Boomsma DI, W J H Penninx B. A role for vitamin D and omega-3 fatty acids in major depression? An exploration using genomics. Transl Psychiatry. 2019 Sep;9(1): 219.

7 Su KP, Lai HC, Yang HT, Su WP, Peng CY, Chang JP, et al. Omega-3 fatty acids in the prevention of interferon-alpha-induced depression: results from a randomized, controlled trial. Biol Psychiatry. 2014 Oct; 76(7):559-66.

\section{KARGER}

E-Mail karger@karger.com www.karger.com/pps
(C) 2019 The Author(s)

Published by S. Karger AG, Basel

This article is licensed under the Creative Commons AttributionNonCommercial-NoDerivatives 4.0 International License (CC BYNC-ND) (http://www.karger.com/Services/OpenAccessLicense). Usage and distribution for commercial purposes as well as any distribution of modified material requires written permission.
Carisha S. Thesing

Department of Psychiatry, Amsterdam UMC

Location Vrije Universiteit Amsterdam

Oldenaller 1, NL-1081 HJ Amsterdam (The Netherlands)

E-Mail c.thesing@vumc.nl 